\title{
Evolução espacial de áreas irrigadas com base em sensoriamento remoto o Médio Vale do Paraíba do Sul, Sudeste do Brasil \\ (doi:10.4136/ambi-agua.7)
}

\author{
Nilton S. Paes Junior; Silvio J. C. Simões \\ Laboratório de Análise Geoespacial (LAGE), Faculdade de Engenharia de Guaratinguetá (UNESP) \\ E-mail: \{paesjunior, simoes\}@feg.unesp.br
}

\section{RESUMO}

Este estudo analisa a evolução espacial das áreas irrigadas na região do Médio Vale do Paraíba do Sul, considerando o período entre 1988 e 2003. O cultivo de arroz de várzea é uma atividade histórica no Vale do Paraíba responsável por cerca de 51\% do consumo de água na bacia. A análise espacial multitemporal foi realizada a partir de classificação supervisionada com o auxílio do software SPRING, utilizando-se imagens Landsat-TM. As quatro regiões analisadas (Guaratinguetá, Tremembé, Pindamonhangaba e Lorena-Canas) representam 82\% de toda a área irrigada na região. Os resultados mostraram, para o período considerado, significativa redução das áreas de irrigação em Lorena-Canas e Pindamonhangaba, respectivamente 32,4 e 22,7\%, enquanto em Tremembé houve a redução menor: 6,4\%. A região de Guaratinguetá foi a única a apresentar um aumento da área irrigada: 14,2\%. Considerando a área total, houve uma redução de 11,8\% no período entre 1988 e 2003 . Esses resultados mostram a tendência inversa ao que ocorre em outras regiões do Estado de São Paulo, as quais tiveram um significativo aumento das áreas de irrigação nas últimas décadas. O avanço da urbanização e a explotação de minerais de agregados são responsáveis pela redução das áreas de arroz irrigado, além de contribuir para a destruição do que resta do ecossistema de áreas úmidas ligadas ao Vale do Paraíba.

Palavras-chave: arroz irrigado; dinâmica do uso da terra; sensoriamento remoto; Vale do Paraíba.

\section{Spatial evolution of irrigated areas using remote sensing - the Medium Paraíba do Sul Valley, Southeast of Brazil}

\begin{abstract}
This study intends to evaluate the spatial analysis of the rice irrigation areas in the Medium Paraíba do Sul Valley for the period comprised between 1988 and 2003. Rice irrigation is a historical activity in Paraiba Valley being responsible for $51 \%$ of the water supply in this region. Supervised Classification was made for the multitemporal interpretation of remote sensing data (Landsat TM) using the software SPRING, ver 3.0. The analysis encompassed four regions (Guaratinguetá, Tremembé, Pindamonhagaba e Lorena-Canas), which represent $82 \%$ of the total irrigated area in the Paraiba Valley. The results show a significant decrease in irrigation area in Lorena-Canas (32.4\%) and Pindamonhangaba (22.7\%) and a smaller one in Tremebé region (6.4\%). In contrast, Guaratinguetá region has presented an increase in irrigation area (14.2\%). For the four regions analyzed, a reduction of $11.8 \%$ in irrigated area has been observed. Unlike other regions of São Paulo State, the irrigation activity in the Paraíba Valley is decreasing notably due to rapid urbanization and
\end{abstract}


mineral extraction near, or on alluvial plan, contributing to the reduction of irrigated rice cultivation and elimination of wetlands ecosystems.

Keywords: irrigation; land use dynamics; remote sensing; Paraíba Valley.

\section{INTRODUÇÃO}

O uso da irrigação vem se difundindo no mundo devido à premissa de se produzir mais, em menores áreas, no menor período de tempo e ao menor custo. Assim, o uso da irrigação tem sido responsável por cerca de $70 \%$ de toda a água utilizada no planeta e teve crescimento de cerca de 130\% (em kmªno) no período compreendido entre 1960 e 2000 (Telles, 2002). Essa magnitude de uso está relacionada tanto ao aumento das áreas agrícolas quanto à variabilidade climática que atinge regiões situadas em diferentes latitudes do planeta. No caso do Brasil, a demanda por agricultura irrigada supera os $60 \%$ quando comparada a todos os demais usos (Lima et al., 1999).

No Estado de São Paulo, ainda que as chuvas sejam relativamente suficientes (em torno de 1376 mm/ano), sua distribuição não é uniforme e a irrigação é largamente utilizada. Dessa forma, a atividade de irrigação no Estado ultrapassa os usos domésticos e industriais, tendo a demanda por recursos hídricos superficiais alcançado $143 \mathrm{~m}^{3} / \mathrm{s}$ (41\% do total). Um levantamento realizado pela Secretaria de Recursos Hídricos do Estado mostra que a área irrigada quintuplicou em um período de 25 anos (1970 a 1995), apresentando crescimento anual médio de 6,5\% (São Paulo, 2002).

No caso do Vale do Paraíba (porção paulista), a atividade de irrigação constitui atividade histórica iniciada nos primórdios do século XX, a qual vem sendo utilizada para garantir boas safras de arroz plantadas nas várzeas do rio Paraíba do Sul e alguns dos seus principais afluentes. Atualmente, a atividade de irrigação no Vale do Paraíba consome $10,2 \mathrm{~m}^{3} / \mathrm{s}$, o que corresponde a $51 \%$ dos recursos hídricos superficiais consumidos na região (São Paulo, 2002).

Nos últimos anos, a bacia do Paraíba do Sul tem chamado a atenção dos especialistas pela dificuldade de garantir, de forma sustentável, água para todos as formas de uso (consuntiva e não-consuntiva), envolvendo os setores agrícola, industrial, energético, doméstico e minerário.

Este artigo tem, como objetivo analisar a evolução espacial das áreas de irrigação no Vale do Paraíba (porção paulista) com base em imagens de satélite no período compreendido entre 1988 e 2003. O uso de sensoriamento remoto vem se tornando um importante auxiliar no gerenciamento das áreas agrícolas, o que tem motivado pesquisas no sentido de melhorar as técnicas e os métodos empregados na classificação das áreas de cultivo (Van Niel e McVicar, 2004). A análise e a classificação de imagens de satélite são, portanto, ferramentas poderosas na geração de informação sobre o uso e cobertura da terra ainda que não sejam capazes de fornecer $100 \%$ de certeza em seus resultados.

Espera-se que os resultados obtidos neste artigo contribuam para o planejamento territorial e para a avaliação da disponibilidade hídrica para as próximas décadas na região.

\section{DESCRIÇÃO DA ÁREA DE ESTUDO}

A área de estudo corresponde à porção paulista da bacia do Rio Paraíba do Sul, a qual constitui uma das bacias independentes que integram a região hidrográfica do leste brasileiro. A superfície da bacia é avaliada em cerca de $57.000 \mathrm{~km}^{2}$ e equivale a pouco menos de $0,7 \%$ 
da área do país e 6\% da superfície da região Sudeste do Brasil. A porção da bacia que está sendo estudada neste trabalho está inserida no Estado de São Paulo (Alto e Médio Vale do Paraíba do Sul), correspondendo a uma extensa área de várzea delimitada por sistemas de serras de orientação SW-NE (figura 1).

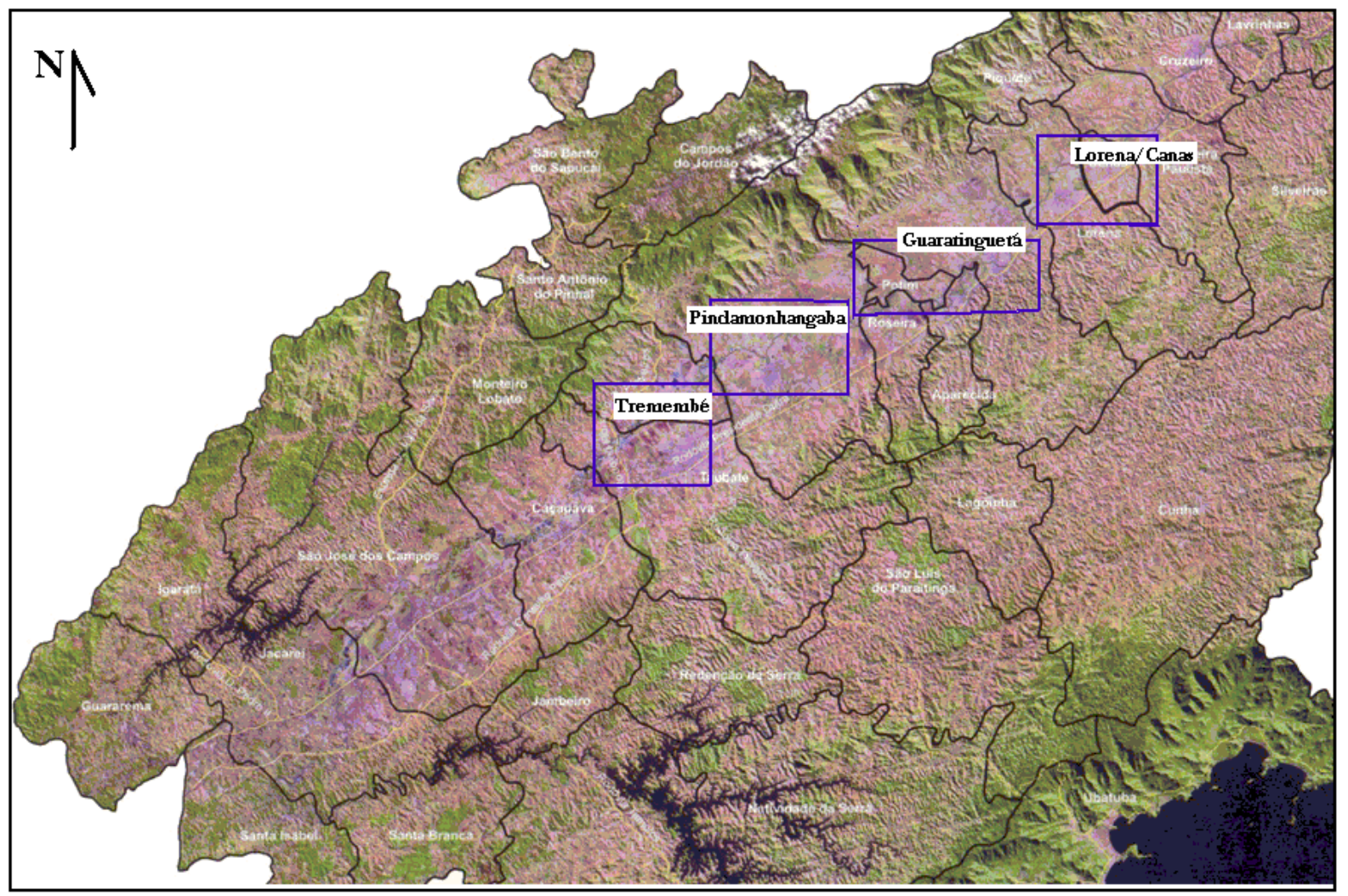

Figura 1. Imagem de satélite Landsat mostrando o Vale do Paraíba e áreas adjacentes com a localização aproximada das quatro áreas de estudo (Tremembé, Pindamonhangaba, Guaratinguetá e Lorena/Canas).

Conforme se pode perceber a partir da figura 1, a bacia do rio Paraíba do Sul possui uma elevada diversidade do meio físico, a qual é produto de uma evolução geológicageomorfológica complexa (IPT, 1981; Ross; Moroz, 1997). Na região são encontradas três unidades geológicas bem distintas: rochas precambrianas, associadas aos relevos de morros e serras; rochas sedimentares terciárias associadas aos relevos colinosos e rochas quaternárias associadas à planície de inundação. Essa grande diversidade do meio físico também favoreceu a evolução de várias unidades pedológicas distintas entre as quais se podem destacar os latossolos, os argissolos, os cambissolos e os organossolos (Oliveira et al., 1999).

A bacia apresenta elevada concentração urbano-industrial localizada ao longo da Rodovia Presidente Dutra. O crescimento populacional na região do Vale do Paraíba (porção paulista) foi vertiginoso, aumentando em cerca de 300\% nos últimos 40 anos. A população passou de aproximadamente 518.000, em 1960, para 1690.000, em 2000 (São Paulo, 2000).

Cidades como São José dos Campos, Taubaté, Jacareí, Pindamonhangaba, Guaratinguetá, Lorena, Caçapava e Cruzeiro contribuem com cerca de $85 \%$ da população e mais de $93 \%$ da produção industrial da região (São Paulo, 2000). A expansão de diferentes centros urbanos foi favorecida pela boa infra-estrutura de transportes, que por sua vez, possibilitou a implantação da atividade industrial no início do século XX e a sua consolidação e diversificação na segunda metade do século passado. 
Do ponto de vista institucional, a bacia do rio Paraíba do Sul apresenta-se como uma das mais complexas do país, pois necessita ajustar conflitos de interesses de três dos principais estados da Federação (São Paulo, Rio de Janeiro e Minas Gerais). Diante dessa complexidade e da excessiva demanda por recursos hídricos, a ANA (Agência Nacional de Águas) considerou a bacia do rio Paraíba do Sul como uma das quatro prioritárias para investimento juntamente com as bacias do Piracicaba/Capivari, Doce e São Francisco.

\subsection{Uso da Terra}

Registros e reconstituições da vegetação do sudeste brasileiro indicam que a região do Vale do Paraíba apresentava-se coberta por uma floresta trópica latifoliada em quase toda a sua extensão. Historicamente, a atividade humana imprimiu transformações dramáticas na paisagem regional do sudeste brasileiro com a redução da área de floresta de aproximadamente 81\% para 8\% nos últimos 300 anos (Fujieda et al., 1997).

Esse processo de desmatamento, embora viesse ocorrendo desde meados do século XVII com o "ciclo da cana-de-açúcar", intensificou-se com a cultura do café, que teve um importante papel na região do Vale do Paraíba e adjacências a partir do século XVIII. Com a decadência do café devido, entre outros fatores, ao esgotamento dos solos e a dificuldade de se obter terras férteis, a principal atividade rural passou a ser a pecuária pela criação extensiva de gado leiteiro e das atividades dela decorrentes. As condições inadequadas de manejo da pecuária na região têm contribuído para a intensa degradação da paisagem e reduzindo as perspectivas de aproveitamento rural dessas áreas. Atualmente, na região, inicia-se, possivelmente, um novo ciclo pela silvicultura (plantio de eucalipto). Caso esses plantios sejam realizados com boas práticas de manejo, podem se constituir em uma alternativa para a recomposição da paisagem nas áreas de pastos/campos degradados.

Em termos de distribuição espacial, as áreas de pastos/campos representam cerca de 50\% da área total da bacia (Tabela 1). Considerando a terminologia utilizada pela Ecologia da Paisagem, essas áreas se constituem no elemento matriz, enquanto os demais usos seriam pedaços (patches) inseridos na matriz (Forman; Godron, 1986; Forman, 1995).

Tabela 1. Estimativas do uso da terra para o Vale do Paraíba (Setor Paulista) a partir da interpretação de imagens de satélite de 1993, 1997 e 1998 (São Paulo, 2000, modificado).

\begin{tabular}{lc}
\hline \multicolumn{1}{c}{ Uso Identificado } & Ocorrência (\%) \\
\hline Matas & 17,4 \\
Capoeiras & 13,4 \\
Campo Natural de Altitude & 0,7 \\
Reflorestamento & 9,0 \\
Campo / Pastagem & 49,4 \\
Pastagem de Várzea & 3,3 \\
Agricultura & 0,4 \\
Agricultura de várzea & 1,0 \\
Áreas com mineração & 0,2 \\
Áreas com solo exposto & 0,2 \\
Área urbanizada & 2,9 \\
Rios, lagos & 0,6 \\
Reservatórios & 1,4 \\
\hline
\end{tabular}

Analisando os dados apresentados na Tabela 1, pode-se constatar uma paisagem com elevado grau de fragmentação na qual se destacam as áreas de mata nativa $(17,4 \%)$, capoeira $(13,4 \%)$, reflorestamento $(9,0 \%)$, pastagem de várzea $(3,3 \%)$, agricultura de várzea $(1,0 \%)$ áreas urbanizadas $(2,9 \%)$ e reservatórios $(1,4 \%)$. 
Embora as áreas de agricultura de várzea sejam relativamente pequenas em relação à área total da bacia $(1,0 \%)$, possuem grande importância na constituição da diversidade da paisagem na região, ocupando parte das extensas áreas da planície aluvionar do rio Paraíba do Sul. Uma outra parte expressiva da várzea (3,3\%) é utilizada para criação de gado; trata-se de uma forma inapropriada de uso devido, entre outros motivos, ao fato do nível freático estar próximo à superfície e ser bastante suscetível à contaminação. As áreas urbanas representam 2,9\% do total e correspondem, principalmente, aos vários núcleos de conurbação (São José dos Campos-Jacareí, Taubaté-Tremebé, Aparecida-Guaratinguetá-Lorena). Parte das áreas urbanas ocupam, inapropriadamente, as áreas de baixíssimas declividades (entre zero e 2\%) ligadas ao rio Paraíba do Sul. As áreas com explotação de agregados minerais, principalmente areia, ocupam uma área relativamente pouco expressiva da bacia (0,2\%). Entretanto, o trecho entre Jacareí e Tremembé é responsável por cerca de $10 \%$ da produção nacional de areia e chama a atenção pelo impacto que ocasiona na paisagem natural.

Tabela 2. Relação das áreas de polders no Vale do Paraíba (São Paulo, 2000).

\begin{tabular}{llcc}
\hline \multicolumn{1}{c}{ Municípios } & Nome dos polders & Áreas (hectares) & Diques (metros) \\
\hline Canas & Caninhas & 140 & 1900 \\
Canas & Canas & 410 & 3900 \\
Lorena & Lorena I & 1800 & 7800 \\
Lorena & Lorena II & 1500 & 8320 \\
Guaratinguetá & Colônia do Piagui & 2200 & 6510 \\
Guaratinguetá & Guaratinguetá & 212 & 4450 \\
Aparecida & Aparecida I & 385 & 7200 \\
Aparecida & Aparecida II & 120 & 5500 \\
Roseira & Roseira II & 1000 & 6200 \\
Pindamonhangaba & Pinda I & 180 & 5100 \\
Pindamonhangaba & Pinda II & 193 & 3200 \\
Pindamonhangaba & Pinda IV & 1400 & 7300 \\
Tremembé & Tremembé I & 2025 & 12400 \\
Tremembé & Tremembé II & 944 & 5300 \\
Tremembé & Tremembé III & 780 & 7400 \\
Taubaté & Quiririm I & 780 & 5200 \\
Total & & 13993 & 97680 \\
\hline
\end{tabular}

\subsection{Irrigação no Vale do Paraíba}

As plantações de arroz foram introduzidas no final do século XVIII, no município de Tremembé com a vinda e instalação dos frades trapistas, que utilizaram as boas características dos terrenos de várzeas e recursos hídricos do Ribeirão da Serragem (Lindemberg, 2001).

Durante a primeira metade do século XX, a cultura do arroz irrigado difundiu-se por toda a região devido à boa característica dos terrenos de várzeas do Rio Paraíba e também pela boa disponibilidade hídrica da bacia. A irrigação foi executada pelo método de inundação permanente no qual a água utilizada é captada, principalmente de rios e córregos, sendo tal processo executado por gravidade na maioria das propriedades.

Embora as áreas de várzea no Vale do Paraíba tivessem potencial produtivo elevado para culturas anuais, sua exploração encontrava sérios empecilhos devido às inundações causadas pelas cheias do rio Paraíba do Sul. Essas cheias afetavam o seu leito secundário e as águas permaneciam por longo tempo, impedindo o aproveitamento das áreas de várzeas.

Em 1951, para atenuar esse problema, o governo do Estado de São Paulo, por meio do seu Departamento de Águas e Energia Elétrica (DAEE), iniciou um trabalho de execução de cortes dos meandros do rio Paraíba do Sul. Muitos dos alinhamentos hoje observados no canal 
principal são devidos às modificações realizadas a partir da década de 50, quando o arroz, plantado em sua várzea, passou a ser encarado como uma atividade comercial.

Pelo convênio com o DAEE, foi elaborado um projeto que previa a retificação do rio Paraíba do Sul, assim como a construção de diques e canais que possibilitariam minimizar os problemas de inundação nas épocas de cheias. Para esse fim foram estabelecidas 42 unidades autônomas, denominadas "polders", que tinham sistema de irrigação e drenagem próprias. Tais polders possibilitariam a exploração de uma área agrícola de cerca de 34.000 ha com uma demanda total de água em torno de $50 \mathrm{~m}^{3} / \mathrm{s}$ durante o ciclo de cultura. Porém, as metas do projeto não foram atingidas, pois o governo priorizou seus investimentos no desenvolvimento do setor industrial na bacia; apenas cerca de 14.000 ha dos 34.000 ha previstos foram ocupados (São Paulo, 2000).

A Tabela 2, lista as áreas protegidas e beneficiadas (polders) com suas respectivas áreas e comprimento dos diques. Verifica-se que os diques têm uma extensão total de $97.680 \mathrm{~m}$ e área total de 13.993 hectares (em torno de $140 \mathrm{~km}^{2}$ ).

\section{MATERIAL E MÉTODOS}

Na identificação e no mapeamento das áreas irrigadas procurou-se utilizar um conjunto de imagens de satélite multi-temporais que permitissem diferenciar, com razoável acuidade, as principais formas de uso da terra e possibilitasse avaliar a evolução das áreas selecionadas por um período de 15 anos (1988 a 2003). As imagens de satélite utilizadas foram Landsat 5, nas bandas 3, 4 e 5 com as cores azul, verde e vermelha, respectivamente com passagens em 03/07/1988, 27/10/1995 e 27/02/2003.

Os procedimentos de interpretação e tratamento de imagem foram executados com o auxílio do programa SPRING (Sistema de Processamento de Informações Georeferenciadas), desenvolvido pelo INPE (Instituto Nacional de Pesquisas Espaciais).

Inicialmente, foi executado o georreferenciamento das imagens, utilizando-se o módulo INPIMA no SPRING e salvando como GRIB. Os pontos de controle foram obtidos a partir das cartas topográficas de Guaratinguetá, Santos e Volta Redonda, do IBGE em escala 1:250.000 (Tabela 3).

Em seguida, foi executado o processo de classificação supervisionada a partir da técnica de Máxima Verossimilhança (Maxver) do software SPRING (Câmara et al., 1996; Shiba et al., 2005). O processo de classificação supervisionada é controlado pelo usuário que seleciona e delimita algumas áreas piloto suficientemente representativas das categorias de uso da terra que irão compor a legenda dos mapas. Para ajudar na seleção de amostras homogêneas de cada classe fez-se uso de mapas cartográficos convencionais e de fotografias aéreas.

Os mapas topográficos utilizados foram em escala 1:50.000, IBGE (folhas Guaratinguetá, Pindamonhangaba, Tremembé, Lorena) e as fotografias aéreas utilizadas foram obtidas em junho de 1973 e maio de 1998 nas escalas 1:25000 e 1:10000, respectivamente. Entretanto, as fotografias aéreas disponíveis cobriam apenas parte da área estudada (região de Guaratinguetá). Visitas de campo também foram determinantes para o processo de classificação de imagens, avaliando situações duvidosas quanto ao uso da terra e definindo coordenadas de pontos de controle com o auxílio de um aparelho de navegação Garmin GPS $\mathrm{II}^{+}$. As dúvidas mais freqüentes envolviam a separação entre as áreas constituídas de arroz irrigado atuais e as áreas de arroz irrigado abandonadas ou ocupadas por pasto. Nessas condições buscou-se selecionar vários campos de pequeno tamanho que tendem a reduzir a variabilidade da categoria em análise quando comparados com campos de maior dimensão (Campbell, 2002; Lillesand; Kiefer, 2004). 
PAES JUNIOR, N. S.; SIMÕES, S. J. C. Evolução espacial de áreas irrigadas com base em sensoriamento remoto o médio Vale do Paraíba do Sul, Sudeste do Brasil. Ambi-Agua, Taubaté, v. 1, n. 1, p. 72-83, 2006. (doi:10.4136/ambi-agua.7)

Tabela 3. Registros dos pontos de controle utilizados.

\begin{tabular}{c|c|cc}
\hline $\begin{array}{c}\text { Pontos de controle } \\
\text { selecionados }\end{array}$ & Localização & \multicolumn{2}{|c}{ Coordenadas } \\
\hline PC -1 & Ponta Grossa (Ubatuba) & 498250 & 7405250 \\
PC -2 & Represa do Funil (Itatiaia) & 539750 & 7510375 \\
PC -3 & Barragem do rio Paraitinga & 432525 & 7416250 \\
PC -4 & Caçandoca (Maranduba) & 478750 & 7392500 \\
PC -5 & Caraguatatuba & 461650 & 7387500 \\
PC -6 & São Sebastião & 459625 & 7376500 \\
\hline
\end{tabular}

Em termos regionais, foram selecionadas quatro áreas em que o cultivo do arroz irrigado se mostra mais expressivo: Lorena-Canas com 3.710 ha, Guaratinguetá (Colônia do Piaguí) com 2.200 ha, Pindamonhangaba com 1.773 ha e Tremembé com 3.749 ha. A área total estudada corresponde a, aproximadamente, $82 \%$ da área total de irrigação (Tabela 2).

Para a seleção das classes temáticas levou-se em conta a identificação dos plantios de arroz de várzea e os tipos de uso existentes no seu entorno. Dessa forma foram identificadas e diferenciadas quatro classes de usos da terra representados por mata, pastagem, plantios de arroz e áreas urbanas.

\section{RESULTADOS E DISCUSSÃO}

Conforme já mencionado, a análise espacial foi direcionada a fim de avaliar a extensão das áreas irrigadas e suas áreas de entorno. As áreas irrigadas da região estudadas situam-se em uma extensa várzea a qual pode ser considerada como uma "área úmida” (wetland), definida como aquelas regiões onde predominam solos hidromórficos e estão saturados em boa parte do ano (Gilman, 1994).

Áreas úmidas cultivadas com arroz, como é o caso da região estudada, são designadas por Anderson et al. (1976) como uma categoria maior, designada “Terra Agrícola”; que difere da categoria "Terra Úmida” na qual ocorre apenas vegetação natural e o ecossistema encontra-se preservado. Para a área de estudo, a definição de uma dessas categorias não é simples devido à paisagem do Vale do Paraíba ser constituída por fragmentos de vegetação natural, pastagem de várzea, arroz de várzea e urbanização. Portanto, a região é formada por um misto de "Terras Agrícolas" (plantio de arroz e pastos), pequenas porções de "Terra Úmida” (vegetação hidrófila) e áreas urbanas e periurbanas.

Com base nos procedimentos descritos no item 3 (Metodologia), foi possível calcular a porcentagem de variação das áreas de plantio de arroz para as quatro áreas selecionadas (Tabela 4).

Tabela 4. Áreas de cultivo de arroz irrigado nos três períodos considerados (em ha).

\begin{tabular}{lcrrc}
\hline Área de estudo & $\mathbf{1 9 8 8}$ & $\mathbf{1 9 9 5}$ & $\mathbf{2 0 0 3}$ & Variação (\%) \\
\hline Guaratinguetá (Piaguí) & 2028,42 & 1997,19 & 2363,46 & 14,2 \\
Lorena/Canas & 1194,39 & 770,31 & 807,39 & $-32,4$ \\
Pindamonhangaba & 5892,12 & 4417,47 & 4554,63 & $-22,7$ \\
Tremembé & 6078,51 & 5543,28 & 5689,89 & $-6,4$ \\
\hline
\end{tabular}

A partir da Tabela 4, pode se observar que todas as sub-regiões apresentaram redução nas áreas de cultivo de arroz com exceção da região Guaratinguetá (Piaguí).

A região Lorena/Canas apresentou a redução mais significativa no período entre 1988 e 2003 (32,4\%). No período entre 1995 e 2003 essa região teve um pequeno acréscimo da área de plantio. A Figura 2 mostra a redução das áreas de plantio na região Lorena/Canas que 
ocorreu principalmente próxima às porções meandradas do rio Paraíba do Sul. De fato, as áreas de irrigação situam-se no eixo de integração urbana entre Lorena (na parte sudoeste da imagem) e Canas (na parte nordeste) conforme se pode observar na figura 2 na comparação entre 1988 e 2003. Além de pressões urbanísticas, uma parte da área de arroz irrigado foi transformada em pastagem. Isso foi observado na visita realizada ao bairro Porto do Meira onde não existem mais as grandes áreas de plantio de arroz identificadas na carta topográfica do IBGE, 1:50.000 de 1967.

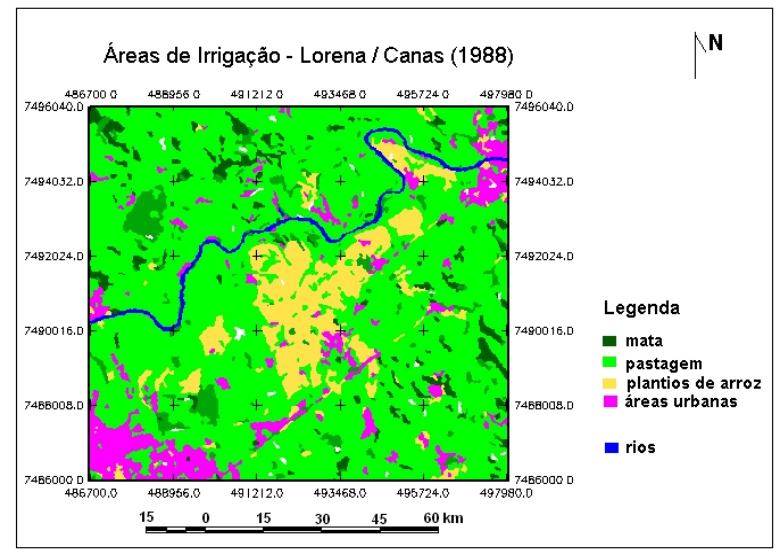

(a)

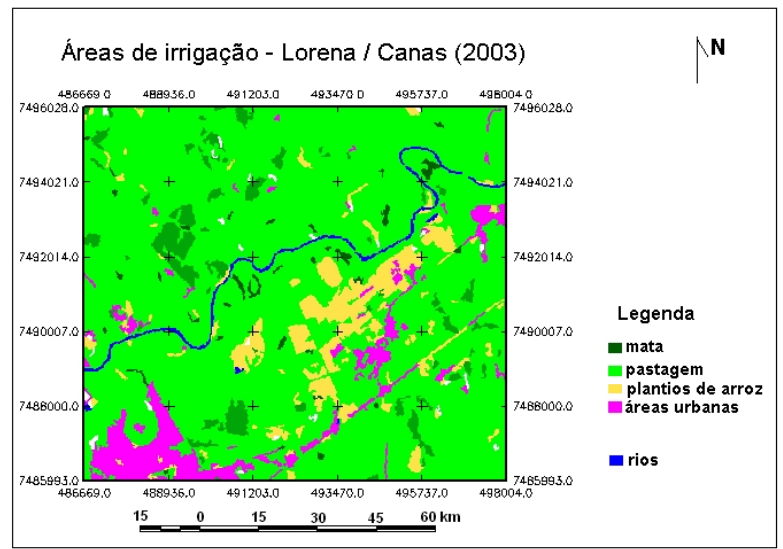

(b)

Figura 2. Evolução das áreas de arroz irrigado na região de Lorena e Canas entre 1988 (a) e 2003 (b).

Para a região de Pindamonhangaba, houve redução da área de cultivo de cerca de 25,0\% entre 1988 e 1995 e um pequeno aumento da ordem de 3,0\% de 1995 e 2003, perfazendo uma redução de 22,7\% entre 1988 e 2003 (Figura 3). Entre todas as regiões analisadas, essa foi a que apresentou uma maior fragmentação e perda de continuidade das áreas de plantio.

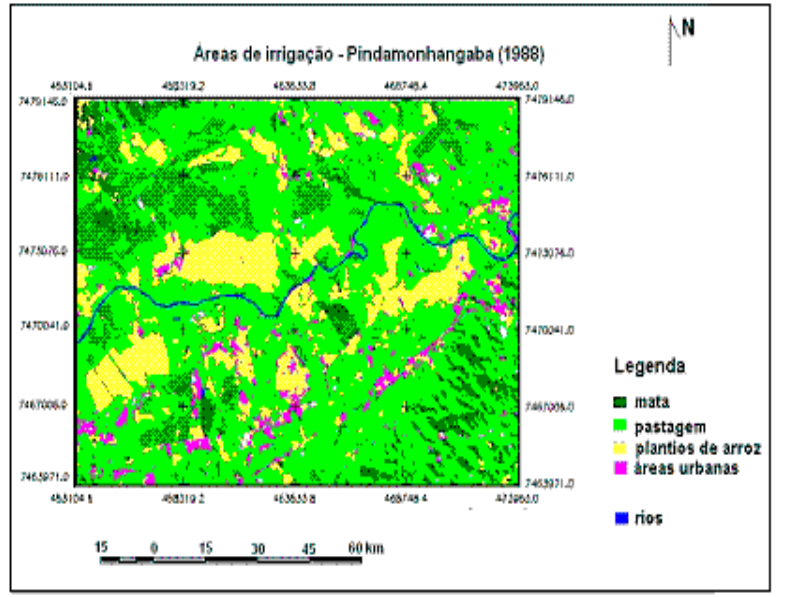

(a)

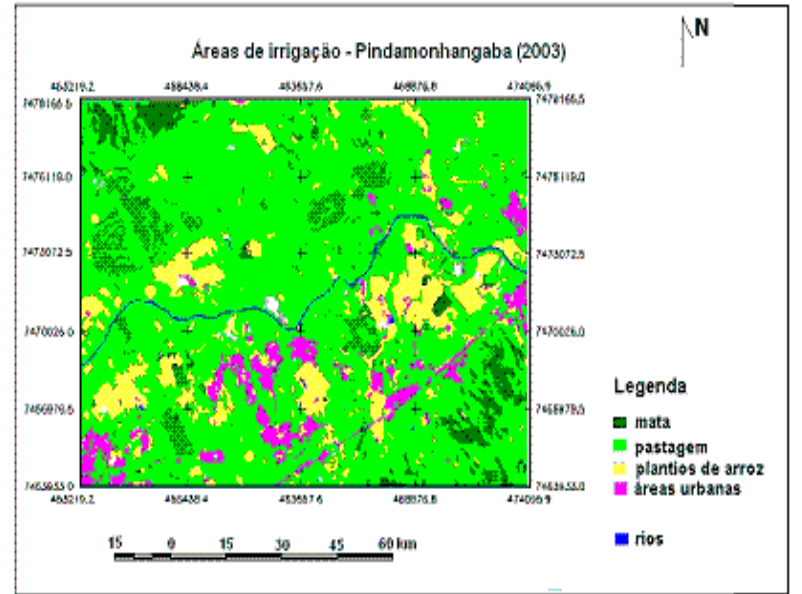

(b)

Figura 3. Evolução das áreas de arroz irrigado na região de Pindamonhangaba entre 1988 (a) e 2003 (b).

Ainda que não existam estudos específicos, a redução das áreas de irrigação na região de Pindamonhangaba pode estar associada ao grande crescimento urbano e industrial nas últimas décadas (São Paulo, 2000), este último apoiado por ações municipais de incentivos fiscais para instalação de empresas do município. Isso tem gerado grandes valorizações do uso da terra o que inviabiliza economicamente o plantio de arroz. 
Com relação à região de Tremembé, pode se observar redução menos significativa, da ordem de 8,8\% entre 1988 e 1995 e 2,6\% entre 1995 e 2003, perfazendo uma redução de 6,4\% entre 1988 e 2003 (Figura 4).

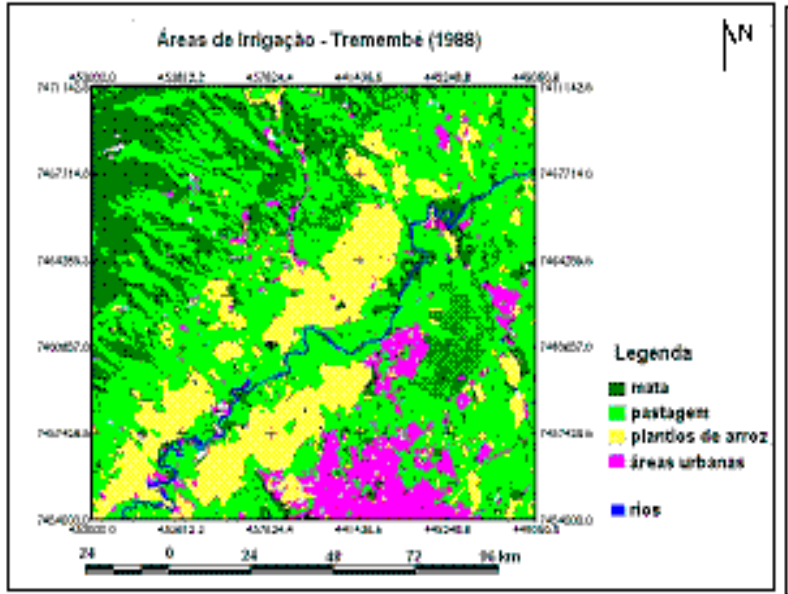

(a)

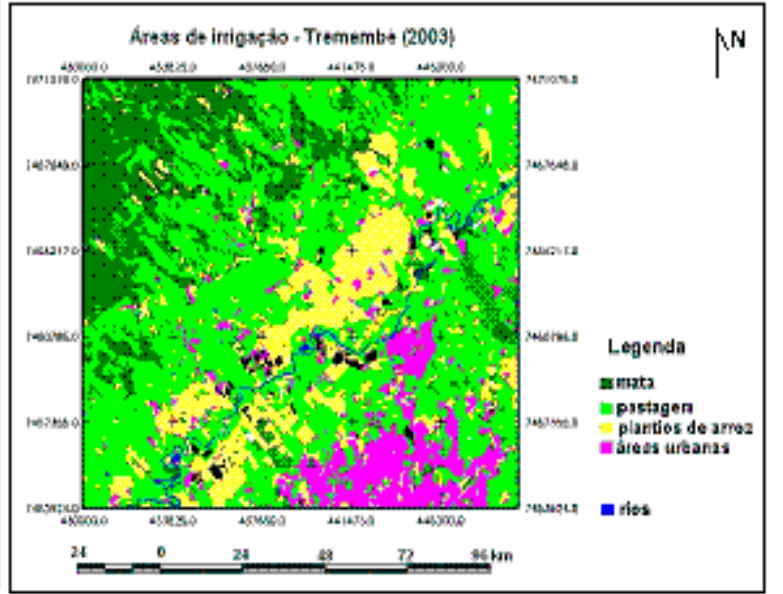

(b)

Figura 4. Evolução das áreas de arroz irrigado na região de Tremembé entre 1988 (a) e 2003 (b).

Em Tremembé, as áreas de plantio de arroz têm sido relativamente preservadas do avanço da urbanização e da industrialização. Entretanto, as áreas urbanas de Tremembé e Taubaté constituem hoje uma única "mancha”, sendo possível que as áreas de plantio de arroz sofram pressões do avanço da urbanização nas próximas décadas. Atualmente, o maior problema está relacionado à atividade de mineração, particularmente os portos de areia com exploração de cavas os quais têm avançado sobre as áreas de polder, contribuído para a redução das áreas agrícolas (Lindenberg, 2001).

Ao contrário das demais, a área de Guaratinguetá apresentou crescimento de 14,2\% no período entre 1988 e 2003 (Figura 5), ainda que tenha tido redução de 9\% no período compreendido entre 1988 e 1995 (Tabela 4).

Na região de Guaratinguetá, a área de irrigação está concentrada na região da Colônia do Piaguí, a qual utiliza a extensa área de várzea do ribeirão homônimo. Na visita ao polder Piaguí foram observados os tabuleiros de arroz e também os canais de condução de água de concreto, além dos silos e secadores de arroz que estão presentes em quase todas as propriedades. A boa estrutura organizacional da colônia contribui para a manutenção e o crescimento da atividade de irrigação, que não cede facilmente às pressões provocadas pelas mudanças de uso da terra como ocorreu em outras regiões do Vale do Paraíba. Apesar desta organização, a análise multitemporal com imagens de satélite e fotografias aéreas mostrou que algumas áreas de plantio de arroz estão sendo substituídas por loteamentos urbanos. 


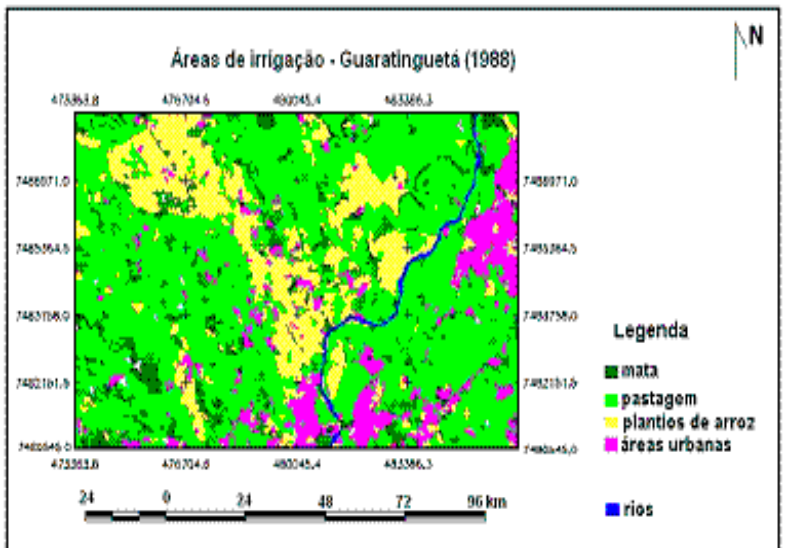

(a)

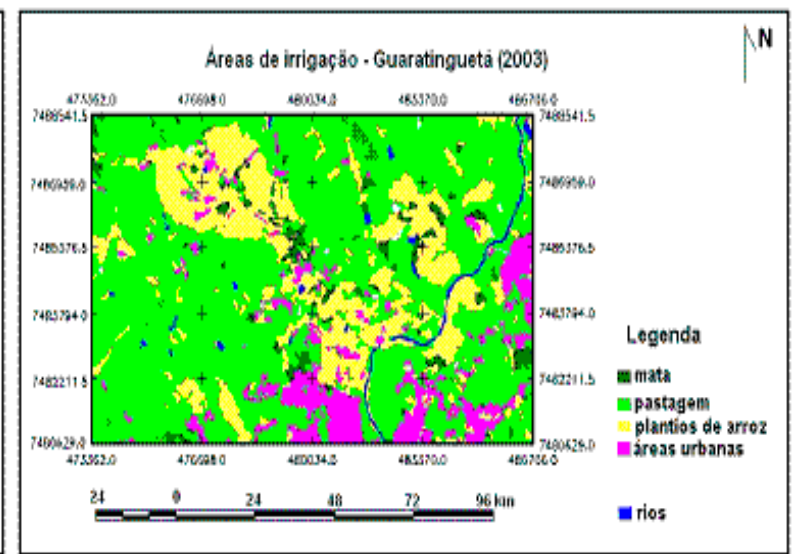

(b)

Figura 5. Evolução das áreas de arroz irrigado na região de Guaratinguetá (Colônia do Piaguí) entre 1988 (a) e 2003 (b).

\section{CONCLUSÕES}

Conforme a tendência mundial, no Estado de São Paulo as áreas de irrigação vêm se expandindo fortemente, crescendo a uma taxa média de 6\% ao ano. Entretanto, no caso do Vale do Paraíba, apesar do plantio de arroz ser uma atividade tradicional, essa tendência não vem ocorrendo. Os resultados obtidos mostram significativas reduções das áreas de plantio de arroz que chegam a alcançar $32,4 \%$ na região de Lorena e $22,7 \%$ na região de Pindamonhangaba e, em menor proporção, na região de Tremembé (6,4\%). A área de Guaratinguetá (Colônia do Piaguí) foi à única que apresentou crescimento positivo, em torno de 14,2\%. Considerando-se o total das quatro regiões analisadas, observa-se redução de 11,8\% na área de plantio no período considerado (1988-2003).

Aspecto positivo na recuperação das áreas agrícolas na várzea é o seu crescimento no período entre 1995 e 2003, observado em todas as áreas estudadas, variando entre 8,4 e 9,7\%. Esse aumento foi interpretado como ligeira recuperação das áreas de irrigação em face da grande redução ocorrida entre 1988 e 1995. Entretanto, é possível que essa tendência de crescimento não continue para os próximos anos, devido à expansão urbana vir cada vez mais ocupando os terrenos de baixíssima declividade $(<2 \%)$.

A rápida mudança na paisagem do Vale do Paraíba demonstra a necessidade de políticas públicas que sejam capazes de reduzir as pressões sobre as áreas de várzeas (naturais e agrícolas). Apesar das restrições físicas e ambientais apresentadas pela várzea do rio Paraíba do Sul, as cidades têm se expandido, substituindo as áreas de plantio de arroz e destruindo o que resta do ecossistema de áreas úmidas.

\section{AGRADECIMENTOS}

À Fundação de Amparo à Pesquisa do Estado de São Paulo/FAPESP pela bolsa de iniciação científica (Processo 02/13494-7). 


\section{REFERÊNCIAS}

ANDERSON, J. R.; HARDY, E. E.; WITMAR, J. T. A land use and land cover classification system for use with remote sensing data. U.S. Geological Survey. Reston: Professional Paper 964, 1976. 28p.

CÂMARA, G.; SOUZA, R. C. M.; FREITAS, U. M.; GARRIDO, J. SPRING: integrating remote sensing and GIS by object-oriented data modeling. Computer Graphics, [S.l.], v. 16, n. 1, p. 395-403, 1996.

CAMPBELL, J. B. Introduction to remote sensing. New York: The Guilford Press, 2002. 621p.

FORMAN, R. T. Land mosaics: the ecology of landscape and regions. Cambridge: University Press, 1995. 632p.

FORMAN, R. T.; GODRON, M. Landscape ecology. New York: John Willey, 1986. 619p.

FUJIEDA, M.; KUDOH, T.; DE CICCO, V.; CARVALHO, J. L. Hydrological processes at the subtropical forest catchments of the Serra do Mar, Sao Paulo, Brazil. Journal of Hydrology, Amsterdam, v. 196, n. 1, p. 26-46, 1997.

GILMAN, K. Hydrology and wetland conservation. New York: Chichester, 1994. 101p.

INSTITUTO DE PESQUISAS TECNOLÓGICAS (São Paulo, SP). Mapa Geológico do Estado de São Paulo. São Paulo, 1981. 1 mapa. Escala 1:500.000. Volume I.

LILLESAND, T. M.; KIEFFER, R. W. Remote sensing and image interpretation. New York : John Wiley \& Sons, 2004. 763p.

LIMA, J. E. F. W.; FERREIRA, R. S. A.; CHRISTOFIDIS, D. O uso da irrigação no Brasil. In: FREITAS, M. A. V. (Ed.). O Estado das Águas no Brasil. Brasília: Ministério das Minas e Energia, 1999. p. 73-82.

LINDENBERG, A. M. Z. Dinâmica da paisagem no Vale do Paraíba: estudo de caso Município de Tremembé. 2001, 112f. Dissertação (Mestrado em Ciências Ambientais) Departamento de Ciências Agrárias, Universidade de Taubaté, Taubaté, 2001.

OLIVEIRA, J. B.; CAMARGO, M. N.; ROSSI, M.; CALDERANO FILHO, B. Mapa pedológico do Estado de São Paulo. Campinas: IAC, 1999.

ROSS, J. L. S.; MOROZ, I. C. Mapa geomorfológico do Estado de São Paulo. São Paulo, 1997. 1 mapa. Escala 1:500.000.

SÃO PAULO (Estado). Comitê de Bacias Hidrográficas. Comitê para integração da bacia hidrográfica do Rio Paraíba do Sul - CEIVAP. Projeto qualidade das águas e controle da poluição hídrica na Bacia do Rio Paraíba do Sul: relatório final. São Paulo: Governo de São Paulo, 2000. 256p. 1 CD-ROM.

- Conselho Estadual dos Recursos Hídricos. Relatório da situação dos recursos hídricos do Estado de São Paulo. São Paulo: Governo do Estado de São Paulo, 2002. 53p.

SHIBA, M. H.; SANTOS, R. L.; QUINTANILHA, J. A.; KIM, H. Y. Classificação de imagens de sensoriamento remoto pela aprendizagem por árvores de decisão: uma 
avaliação de desempenho. In: SIMPÓSIO BRASILEIRO DE SENSORIAMENTO REMOTO, 12., 16-21 abril 2005, Goiânia. Anais... Goiânia: [S.n.], 2005. p. 4319-4326.

TELLES, D. A. Água na agricultura e na pecuária. In: REBOUÇAS, A.; BRAGA, B.; TUNDISI, J. G. (Ed.). Águas doces no Brasil. São Paulo: Escrituras, 2002. p. 305-337.

VAN NIEL, T. G.; MC VICAR, T. R. Determining temporal windows for crop discrimination with remote sensing: a case study in south-eastern Australia. Computer and Electronics in Agriculture, Oxford, v. 45, p. 91-108, 2004. 